Proc. Indian Acad. Sci. (Chem. Sci.), Vol. 98, No. 3, March 1987, pp. 193-197.

(C) Printed in India.

\title{
Copper(II), nickel(II), palladium(II) and iron(III) complexes of 2-(3-phthalhydrazidylazo)-1,3-diketones
}

\author{
K KRISHNANKUTTY and N THANKARAJAN* \\ Department of Chemistry, University of Calicut, Calicut 673635 , India. \\ MS received 28 July 1986
}

\begin{abstract}
Neutral complexes of three phthalhydrazidylazo-1,3-diketones (phthalhydrazidylazo-acetylacetone ( $\left.\mathrm{H}_{2} \mathrm{PAA}\right)$, -benzoylacetone $\left(\mathrm{H}_{2} \mathrm{PBA}\right)$ and -dibenzoylmethane $\left.\left(\mathrm{H}_{2} \mathrm{PDM}\right)\right]$ with $\mathrm{Cu}(\mathrm{II}), \mathrm{Ni}(\mathrm{II}), \mathrm{Pd}(\mathrm{II})$ and $\mathrm{Fe}(\mathrm{III})$ have been synthesised and characterized on the basis of their analytical data, magnetic moment, molar conductance and IR and ${ }^{2} \mathrm{H}$ NMR spectral data. Dibasic tridentate coordination of the ligands is brought out by the above spectral data. Half-wave potentials and far IR spectral data of the $\mathrm{Cu}$ (II) complexes indicate that the $\mathrm{H}_{2}$ PAA complex is the most stable. Mössbauer spectra of the Fe(III) complexes reveal that delocalisation of the metal $d$ electrons with the chelate ring decreases with increasing capability of the pendant groups of the ring for cross conjugation.
\end{abstract}

Keywords. Phthalhydrazidylazo-1,3-diketones; transition metal complexes; IR spectra; NMR spectra; Mössbauer spectra; stability of complexes.

\section{Introduction}

Extensive literature is available on metal chelates of $o, o^{\prime}$-disubstituted diarylazo compounds, which have significant application as stable dyestuffs and as analytical reagents (Venkataraman 1952; Price 1970). However, very few reports exist on metal complexes of azo dyes formed from heterocyclic amines via diazotization, and coupling with the reactive methylene group of $\beta$-diketones. Details of the synthesis and characterization of $\mathrm{Cu}$ (II), $\mathrm{Ni}(\mathrm{II}), \mathrm{Pd}(\mathrm{II})$ and $\mathrm{Fe}$ (III) complexes of three phthalhydrazidylazo-1,3-diketones prepared from 3-aminophthalhydrazide (the chemiluminescent organic compound well-known by its trivial name 'luminol') are brought out in this paper, the 1,3-diketones used being acetylacetone, benzoylacetone and dibenzoylmethane.

\section{Experimental}

\subsection{Preparation of 2-(3-phthalhydrazidylazo)-1,3-diketones}

Phthalhydrazidylazoacetylacetone $\left(\mathrm{H}_{2} \mathrm{PAA}\right)$, phthalhydrazidylazo-benzoylacetone ( $\left.\mathrm{H}_{2} \mathrm{PBA}\right)$ and phthalhydrazidylazodibenzoylmethane $\left(\mathrm{H}_{2} \mathrm{PDM}\right)$ were prepared as reported earlier (Thankarajan et al 1986).

\footnotetext{
* To whom all correspondence should be addressed.
} 


\subsection{Preparation of metal complexes}

Copper(II) complexes were prepared by adding an aqueous solution $(15 \mathrm{ml})$ of the metal(II) acetate $(2.5 \mathrm{mmol})$ to a stirred ethanolic solution $(100 \mathrm{ml})$ of the ligand $(2.5 \mathrm{mmol})$ maintained at $\sim 60^{\circ} \mathrm{C}$. After refluxing the mixture for $2 \mathrm{hr}$, the precipitated complex was filtered, washed successively with water, ethanol and diethyl ether, and then dried in vacuum. For preparing palladium(II) complexes, palladium(II) chloride $(0.215 \mathrm{~g}, 1 \mathrm{mmol})$ dissolved in acetone $(25 \mathrm{ml})$ was added to a hot and stirred solution $(50 \mathrm{ml})$ of the ligand $(1 \mathrm{mmol})$. The mixture was refluxed for about $1 \mathrm{hr}$, the precipitated complex filtered, washed with ethanol, and recrystallised from hot ethanol.

Iron(III) complexes were prepared by mixing an ethanolic solution $(10 \mathrm{ml})$ of iron(III) chloride hexahydrate $(0 \cdot 135 \mathrm{~g}, 5 \mathrm{mmol})$ with a hot and stirred solution of the ligand $(5 \mathrm{mmol})$ in ethanol $(50 \mathrm{ml})$. The deep brown precipitate formed on adding sodium acetate $(0 \cdot 1 \mathrm{~g})$ was filtered, washed with very dilute acetic acid and ethanol, and then dried in vacuum.

\subsection{Physical measurements}

Molar conductance was measured at $28 \pm 0 \cdot 2^{\circ} \mathrm{C}$ in ethanol $\left(10^{-3} \mathrm{M}\right)$ using a Toshniwal conductivity bridge. Magnetic susceptibilities were determined at room temperature on a Gouy type magnetic balance. Infrared spectra (Nujol mull and $\mathrm{KBr}$ disc) were recorded on a Perkin-Elmer 257 spectrometer, and far IR spectra (CsI disc) on a polytech FIR spectrometer. 'H NMR spectra (DMSO- $d_{6}$ ) were obtained from a Varian XL-100 FT NMR spectrometer. For recording Mössbauer spectra (natural iron as reference), a constant acceleration Mössbauer spectrometer ECIL MBS 35 coupled to a multichannel analyser NCA 38 was used. Polarograms were recorded in aqueous pyridine $(50 \% \mathrm{v} / \mathrm{v})$ using $\mathrm{KNO}_{3}$ as supporting electrolyte on an Elico pen recording polarograph. Carbon, hydrogen and nitrogen percentages reported are by microanalyses, and metal contents by standard gravimetric procedures.

\section{Results and discussion}

All complexes behave as non-electrolytes (specific conductance $<10 \mathrm{ohm}^{-1} \mathrm{~cm}^{2} \mathrm{~mol}^{-1}$ ), and do not contain the anion of the metal salt used for preparing them. Nickel(II) and palladium(II) complexes are diamagnetic, while copper(II) complexes show normal magnetic moments of 1.78-1.82 B.M. Magnetic moment of the iron(III) complexes are in the high spin range of 5.90-5.95 B.M. Based on elemental analysis, molar conductance and magnetic moment data the complexes are represented as in table 1.

\subsection{IR spectra}

Infrared and ${ }^{1} \mathrm{H}$ NMR spectral data indicate that the three phthalhydrazidylazo- $\beta$ diketones exist as hydrogen bonded hydrazoneenol, as in the structure I (Thankarajan et al 1986). Thus, while the IR spectrum of $\mathrm{H}_{2} \mathrm{PAA}$ showed a strong band at $1672 \mathrm{~cm}^{-1}$ for free acetyl carbonyl, spectra of $\mathrm{H}_{2} \mathrm{PBA}$ and $\mathrm{H}_{2} \mathrm{PDM}$ showed 
Table 1. Analytical data and other details about the metal complexes of 2-(3-phthalhydrazidylazo)-1,3-diketones.

\begin{tabular}{|c|c|c|c|c|c|c|c|}
\hline \multirow[b]{2}{*}{ Complex } & \multirow{2}{*}{$\begin{array}{l}\text { Yield } \\
(\%)\end{array}$} & \multirow{2}{*}{$\begin{array}{l}\text { M.P. } \\
\left({ }^{\circ} \mathrm{C}\right)\end{array}$} & \multirow{2}{*}{$\begin{array}{c}\boldsymbol{\mu}_{\mathrm{eff}} \\
(\mathbf{B} . \mathbf{M})\end{array}$} & \multicolumn{4}{|c|}{ Found (Calcd.) (\%) } \\
\hline & & & & $\mathrm{C}$ & $\mathbf{H}$ & $\mathbf{N}$ & Metal \\
\hline$\left[\mathrm{Cu}(\mathrm{PAA})\left(\mathrm{H}_{2} \mathrm{O}\right)\right]$ & 65 & a & 1.82 & $\begin{array}{c}42 \cdot 01 \\
(42 \cdot 44)\end{array}$ & $\begin{array}{c}2.98 \\
(3 \cdot 27)\end{array}$ & $\begin{array}{c}14 \cdot 86 \\
(15 \cdot 23)\end{array}$ & $\begin{array}{c}17 \cdot 12 \\
(17 \cdot 28)\end{array}$ \\
\hline$\left[\mathrm{Cu}(\mathrm{PBA})\left(\mathrm{H}_{2} \mathrm{O}\right)\right]$ & 58 & a & $1 \cdot 79$ & $\begin{array}{c}49 \cdot 68 \\
(50 \cdot 28)\end{array}$ & $\begin{array}{c}3 \cdot 13 \\
(3 \cdot 25)\end{array}$ & $\begin{array}{c}12 \cdot 86 \\
(13 \cdot 03)\end{array}$ & $\begin{array}{c}14 \cdot 56 \\
(14 \cdot 79)\end{array}$ \\
\hline$\left[\mathrm{Cu}(\mathrm{PDM})\left(\mathrm{H}_{2} \mathrm{O}\right)\right]$ & 55 & a & $1 \cdot 78$ & $\begin{array}{c}55 \cdot 73 \\
(56 \cdot 15)\end{array}$ & $\begin{array}{c}3 \cdot 09 \\
(3 \cdot 26)\end{array}$ & $\begin{array}{c}11 \cdot 01 \\
(11 \cdot 39)\end{array}$ & $\begin{array}{c}12 \cdot 78 \\
(12 \cdot 93)\end{array}$ \\
\hline$\left[\mathrm{Ni}(\mathrm{PAA})\left(\mathrm{H}_{2} \mathrm{O}\right)\right]$ & 65 & 328 & D & $\begin{array}{c}42 \cdot 59 \\
(43.01)\end{array}$ & $\begin{array}{c}3 \cdot 20 \\
(3 \cdot 31)\end{array}$ & $\begin{array}{c}15 \cdot 10 \\
(15 \cdot 44)\end{array}$ & $\begin{array}{c}15 \cdot 91 \\
(16 \cdot 18)\end{array}$ \\
\hline$\left[\mathrm{Ni}(\mathrm{PBA})\left(\mathrm{H}_{2} \mathrm{O}\right)\right]$ & 50 & 296 & D & $\begin{array}{c}50 \cdot 13 \\
(50 \cdot 86)\end{array}$ & $\begin{array}{c}3 \cdot 08 \\
(3 \cdot 29)\end{array}$ & $\begin{array}{c}12 \cdot 93 \\
(13 \cdot 19)\end{array}$ & $\begin{array}{c}13 \cdot 16 \\
(13 \cdot 82)\end{array}$ \\
\hline$\left[\mathrm{Ni}(\mathrm{PDM})\left(\mathrm{H}_{2} \mathrm{O}\right)\right]$ & 45 & 254 & D & $\begin{array}{c}55.98 \\
(56 \cdot 71)\end{array}$ & $\begin{array}{c}2 \cdot 86 \\
(3 \cdot 29)\end{array}$ & $\begin{array}{c}11 \cdot 12 \\
(11 \cdot 50)\end{array}$ & $\begin{array}{c}11 \cdot 78 \\
(12 \cdot 06)\end{array}$ \\
\hline$\left[\mathrm{Pd}(\mathrm{PAA})\left(\mathrm{H}_{2} \mathrm{O}\right)\right]$ & 60 & $350 \mathrm{~d}$ & D & $\begin{array}{c}38 \cdot 23 \\
(38 \cdot 80)\end{array}$ & $\begin{array}{c}2 \cdot 56 \\
(2 \cdot 98)\end{array}$ & $\begin{array}{c}13 \cdot 12 \\
(13 \cdot 65)\end{array}$ & \\
\hline$\left[\mathrm{Pd}(\mathrm{PBA})\left(\mathrm{H}_{2} \mathbf{Q}\right)\right]$ & 70 & $285 d$ & D & $\begin{array}{c}44 \cdot 86 \\
(45 \cdot 33)\end{array}$ & $\begin{array}{c}2 \cdot 69 \\
(2 \cdot 95)\end{array}$ & $\begin{array}{c}11 \cdot 33 \\
(11 \cdot 85)\end{array}$ & \\
\hline$\left[\mathrm{Pd}(\mathrm{PDM})\left(\mathrm{H}_{2} \mathrm{O}\right)\right]$ & 75 & $220 \mathrm{~d}$ & $\mathrm{D}$ & $\begin{array}{c}51.06 \\
(51.45)\end{array}$ & $\begin{array}{c}2 \cdot 45 \\
(2 \cdot 98)\end{array}$ & $\begin{array}{c}9.97 \\
(10.48)\end{array}$ & \\
\hline$\left[\mathrm{Fe}(\mathrm{PAA})(\mathrm{OH})\left(\mathrm{H}_{2} \mathrm{O}\right)_{2}\right]$ & 62 & $\mathbf{a}$ & 5.91 & $\begin{array}{c}39.76 \\
(40.33)\end{array}$ & $\begin{array}{c}3 \cdot 78 \\
(3 \cdot 88)\end{array}$ & $\begin{array}{c}13 \cdot 86 \\
(14 \cdot 18)\end{array}$ & $\begin{array}{c}14 \cdot 00 \\
(14 \cdot 14)\end{array}$ \\
\hline$\left[\mathrm{Fe}(\mathrm{PBA})(\mathrm{OH})\left(\mathrm{H}_{2} \mathrm{O}\right)_{2}\right]$ & 58 & a & $5 \cdot 93$ & $\begin{array}{c}47 \cdot 88 \\
(48 \cdot 12)\end{array}$ & $\begin{array}{c}3.69 \\
(3.79)\end{array}$ & $\begin{array}{c}12 \cdot 15 \\
(12 \cdot 25)\end{array}$ & $\begin{array}{c}12 \cdot 16 \\
(12 \cdot 22)\end{array}$ \\
\hline$\left[\mathrm{Fe}(\mathrm{PDM})(\mathrm{OH})\left(\mathrm{H}_{2} \mathrm{O}\right)_{2}\right]$ & 56 & $\mathbf{a}$ & $5 \cdot 94$ & $\begin{array}{c}53.69 \\
(54.03)\end{array}$ & $\begin{array}{c}3 \cdot 58 \\
(3 \cdot 72)\end{array}$ & $\begin{array}{c}10.58 \\
(10 \cdot 79)\end{array}$ & $\begin{array}{c}10.83 \\
(10.96)\end{array}$ \\
\hline
\end{tabular}

$\mathrm{a}=$ does not melt or decompose below $350^{\circ} \mathrm{C} ; \mathrm{d}=$ decomposes; $\mathrm{D}=$ diamagnetic.

strong bands at $\sim 1660 \mathrm{~cm}^{-1}$ for free benzoyl carbonyl. Spectra of all the three ligands showed strong bands at $\sim 1650 \mathrm{~cm}^{-1}$ for the amide carbonyl of the phthalhydrazide moiety, and strong and broad bands at $\sim 1615 \mathrm{~cm}^{-1}$ for the internally hydrogen-bonded carbonyl of the $\beta$-diketone moiety.

In the spectra of the metal complexes, the latter band almost disappeared, but instead, another strong band, assignable to the stretching of the coordinated carbonyl of the $\beta$-diketone moiety appeared at $\sim 1550 \mathrm{~cm}^{-1}$ (Nakamoto 1978; Thankarajan and Krishnankutty 1984). A weak band observed at $-1620 \mathrm{~cm}^{-1}$ in the spectra of the metal complexes is probably due to $\nu \mathrm{C}=\mathrm{N}$, which might have been masked by the stronger carbonyl bands in the spectra of the ligands. A very broad band of the ligand at $3500-2400 \mathrm{~cm}^{-1}$, due presumably to hydrogen-bonded $\mathrm{OH} / \mathrm{NH}$ stretching, is replaced in the spectra of the metal complexes by a weaker broad band at $3550-3350 \mathrm{~cm}^{-1}$, attributable to the amide $\mathrm{N}-\mathrm{H}$, and coordinated water. In the case of iron(III) complexes, their coordinated $\mathrm{OH}$ groups caused strong absorption and peak formation at $\sim 3570 \mathrm{~cm}^{-1}$, in addition to a band at $\sim 1130 \mathrm{~cm}^{-1}$ for $\mathrm{Fe}-\mathrm{OH}$ bonding (Nakamoto 1978). 
<smiles>[R2]C(=O)c1nn(-c2cccc3c(=O)[nH]nc(O)c23)c(O)c1[R2]</smiles>

I<smiles>[M]Oc1n[nH]c(=O)c2cccc(N(N=C(C([R])=O)C([R])=O)OC)c12</smiles>

II

Chart 1.

\section{$3.2{ }^{1} \mathrm{H} N M R$ spectra of palladium(II) complexes}

Further evidence for the bonding mode of the ligands (structure II) is provided by the ${ }^{1} \mathrm{H}$ NMR spectra of their palladium(II) complexes. The non-equivalence of the two methyl protons $(2 \cdot 30$ and $2.65 \delta)$ of $\mathrm{H}_{2}$ PAA (Thankarajan et al 1986) persists in its complex, $(2 \cdot 35$ and $2 \cdot 72 \delta)$. A low field broad one-proton signal at $\sim 14 \delta$ in the spectra of all the three ligands for hydrogen-bonded NH disappeared in the spectra of the complexes, indicating replacement of the $\mathrm{NH}$ proton during metal chelation. A comparatively broad one-proton signal at $\sim 5.4 \delta$ for the amide proton of the phthalhydrazide ring is present in the spectra of the ligands and of the metal complexes. The signal for the $\mathrm{OH}$ proton of the ligands could not be located in their spectra, presumably due to fast exchange.

\subsection{Stability of copper(II) complexes}

Order of stability on the basis of polarographic reduction potentials (table 2) of the three copper(II) complexes is $-\left[\mathrm{Cu}(\mathrm{PAA})\left(\mathrm{H}_{2} \mathrm{O}\right)\right]>$ $\left[\mathrm{Cu}(\mathrm{PBA})\left(\mathrm{H}_{2} \mathrm{O}\right)\right]>\left[\mathrm{Cu}(\mathrm{PDM})\left(\mathrm{H}_{2} \mathrm{O}\right)\right]$. Cross conjugation by pendant group(s) seems responsible for the destabilisation of metal chelates of $\mathrm{H}_{2} \mathrm{PBA}$ and $\mathrm{H}_{2} \mathrm{PDA}$. Data for $\nu(\mathrm{Cu}-\mathrm{N})$ and $\nu(\mathrm{Cu}-\mathrm{O})$ from far IR spectra of the complexes (table 2) are in agreement with the stability order. 
Table 2. Half-wave potentials and far IR data of copper(II) complexes.

\begin{tabular}{lcccc}
\hline Complex & $\begin{array}{c}E_{1 / 2}(\mathrm{~V}) \\
\text { First wave }\end{array}$ & $\begin{array}{c}\nu_{\mathrm{Cu}-\mathrm{N}} \\
\left(\mathrm{cm}^{-1}\right)\end{array}$ & $\begin{array}{c}\nu_{\mathrm{Cu}-\mathrm{O}} \\
\left(\mathrm{cm}^{-1}\right)\end{array}$ \\
\hline$\left[\mathrm{Cu}(\mathrm{PAA})\left(\mathrm{H}_{2} \mathrm{O}\right)\right]$ & -0.380 & 560 & 460 & 425 \\
& & & & 360 \\
{$\left[\mathrm{Cu}(\mathrm{PBA})\left(\mathrm{H}_{2} \mathrm{O}\right)\right]$} & -0.365 & 548 & 453 & 418 \\
& & & & 368 \\
{$\left[\mathrm{Cu}(\mathrm{PDM})\left(\mathrm{H}_{2} \mathrm{O}\right)\right]$} & -0.350 & 535 & 450 & 415 \\
& & & & 370 \\
\hline
\end{tabular}

Table 3. Mössbauer spectral data of iron(III) complexes.

\begin{tabular}{lcc}
\hline Complex & $\delta(\mathrm{mm} / \mathrm{s})$ & $\Delta E_{q}(\mathrm{~mm} / \mathrm{s})$ \\
\hline$\left[\mathrm{Fe}(\mathrm{PAA})(\mathrm{OH})\left(\mathrm{H}_{2} \mathrm{O}\right)_{2}\right]$ & +0.331 & 0.963 \\
{$\left[\mathrm{Fe}(\mathrm{PBA})(\mathrm{OH})\left(\mathrm{H}_{2} \mathrm{O}\right)_{2}\right]$} & +0.368 & 0.959 \\
{$\left[\mathrm{Fe}(\mathrm{PDM})(\mathrm{OH})\left(\mathrm{H}_{2} \mathrm{O}\right)_{2}\right]$} & +0.389 & 0.955 \\
\hline
\end{tabular}

\subsection{Mössbauer spectra of iron(III) complexes}

Effect of cross resonance by pendant group on $d$ electron delocalisation with the metal chelate ring was examined from Mössbauer spectral data of the iron(III) complexes. It is evident from observed $\delta$ values (table 3 ) that $d$ electron delocalisation with the chelate ring decreases when the pendant groups of chelate ring are changed from acetyl to benzoyl, and methyl to phenyl. Thus, it is evident that any cross conjugation of the metal chelate ring is not conducive to $d$ electron delocalisation with the ring. Observed $\Delta E_{Q}$ values reveal that increased $d$ electron delocalisation with the chelate ring increases the field gradient at the nucleus.

\section{References}

Nakamoto K 1978 Infrared and Raman spectra of inorganic and coordination compounds (New York: Wiley)

Price R 1970 The chemistry of synthetic dyes (ed.) Venkataraman K (New York: Academic Press) vol. 3, p. 303

Thankarajan N, Krishnankutty K and Srinivasan T K K $1986 \mathrm{~J}$. Indian Chem. Soc. (in press)

Thankarajan N and Krishnankutty K 1984 Indian J. Chem. A23 401

Venkataraman K 1952 The chemistry of synthetic dyes (New York: Academic Press) vol. 1 